\title{
Bronchial blocker versus left double-lumen endotracheal tube in video-assisted thoracoscopic surgery: a randomized-controlled trial examining time and quality of lung deflation Comparaison du bloqueur bronchique à la sonde endotrachéale à double lumière gauche en chirurgie thoracoscopique vidéoassistée: une étude randomisée contrôlée examinant le temps et la qualité de l'affaissement du poumon
}

\author{
Jean S. Bussières, MD · Jacques Somma, MD, BEng • José Luis Carrasco del Castillo, MD • \\ Jérôme Lemieux, MD · Massimo Conti, MD · Paula A. Ugalde, MD · Nathalie Gagné, PhD, RRT • \\ Yves Lacasse, MD
}

Received: 12 June 2015/Revised: 28 January 2016/Accepted: 18 April 2016/Published online: 2 May 2016 (C) Canadian Anesthesiologists' Society 2016

\begin{abstract}
Introduction Double-lumen endotracheal tubes (DL-ETT) and bronchial blockers $(B B)$ have both been used for lung isolation in video-assisted thoracic surgery (VATS). Though not well studied, it is widely thought that a DLETT provides faster and better quality lung collapse. The aim of this study was to compare a BB technique vs a leftsided DL-ETT strategy with regard to the time and quality
\end{abstract}

This article is accompanied by an editorial. Please see Can J Anesth 2016; 63: this issue.

J. S. Bussières, MD · J. Somma, MD, BEng

J. L. C. del Castillo, MD - J. Lemieux, MD

Department of Anesthesiology, IUCPQ-UL, Quebec City, QC, Canada

J. S. Bussières, MD · N. Gagné, PhD, RRT

Research Centre, IUCPQ-UL, Quebec City, QC, Canada

J. S. Bussières, MD $(\square)$

Institut universitaire de cardiologie et de pneumologie de Québec - Université Laval, 2725, Chemin Sainte-Foy,

Quebec City, QC G1V 4G5, Canada

e-mail: jbuss@criucpq.ulaval.ca

M. Conti, MD - P. A. Ugalde, MD

Department of Thoracic Surgery, IUCPQ-UL, Quebec City, QC, Canada

Y. Lacasse, MD

Pneumology Center, IUCPQ-UL, Quebec City, QC, Canada of lung collapse during one-lung ventilation (OLV) for elective VATS.

Methods Forty patients requiring OLV for VATS were randomized to receive a $B B(n=20)$ or a left-sided $D L$ ETT $(n=20)$. The primary endpoint was the time from pleural opening (performed by the surgeon) until complete lung collapse. The time was evaluated offline by reviewing video recorded during the VATS. The quality of lung deflation was also graded offline using a visual scale ( $1=$ no lung collapse; 2 = partial lung collapse; and $3=$ total lung collapse) and was recorded at several time points after pleural incision. The surgeon also graded the time to complete lung collapse and quality of lung deflation during the procedure. The surgeon's guess as to which device was used for lung isolation was also recorded.

Results $O$ f the 40 patients enrolled in the study, 20 patients in the DL-ETT group and 18 in the BB group were analyzed. There mean (standard deviation) time to complete lung collapse of the operative lung was significantly faster using the BB compared with using the DL-ETT [7.5 (3.8) min vs 36.6 (29.1) min, respectively; mean difference, $29.1 \mathrm{~min} ; 95 \%$ confidence interval, 1.8 to $7.2 ; P<0.001]$. Overall, a higher proportion of patients in the BB group than in the DL-ETT group achieved a quality of lung collapse score of 3 at five minutes (57\% vs 6\%, respectively; $P<0.004$ ), ten minutes (73\% vs $14 \%$, respectively; $P=0.005)$, and $20 \min (100 \%$ vs $25 \%$, respectively; $P=0.002)$ after opening the pleura. The surgeon incorrectly guessed the type of device used in $78 \%$ of the BB group and 50\% of the DL-ETT group $(P=0.10)$. 
Conclusion The time and quality of lung collapse during OLV for VATS was significantly better when using a BB than when using a left-sided DL-ETT. Surgeons could not reliably determine which device was being used based on the time and quality of lung collapse. This trial was registered at ClinicalTrials.gov number, NCT01615263.

\section{Résumé}

Introduction Les sondes endotrachéales à double lumière (SET-DL) et les bloqueurs bronchiques (BB) ont tous deux été utilisés pour isoler un poumon pendant une chirurgie thoracique vidéo-assistée (CTVA). Bien que peu étudié, on pense communément qu'une SET-DL procure un affaissement $d u$ poumon plus rapide et de meilleure qualité. L'objectif de cette étude était de comparer une technique avec $B B$ à une stratégie de SET-DL du côté gauche en ce qui touche le temps et la qualité de l'affaissement pulmonaire pendant une ventilation unipulmonaire (VUP) pour une CTVA élective.

Méthode Quarante patients nécessitant une VUP pour une $C T V A$ ont été randomisés à recevoir un $B B(n=20)$ ou une SET-DL du côté gauche $(n=20)$. Le critère d'évaluation principal était le temps entre l'ouverture pleurale (réalisée par le chirurgien) et le dégonflement complet du poumon. Cet intervalle a été évalué hors ligne en passant en revue les enregistrements vidéo réalisés pendant la CTVA. La qualité $d u$ dégonflement du poumon a également été notée hors ligne à l'aide d'une échelle visuelle $(1=$ aucun dégonflement $d u$ poumon; 2 = dégonflement partiel $d u$ poumon; et $3=$ dégonflement complet du poumon) et a été enregistrée à différents moments dans le temps après l'incision pleurale. Le chirurgien a également noté le temps nécessaire à dégonfler le poumon et la qualité de dégonflement $d u$ poumon pendant l'intervention. La supposition du chirurgien quant au dispositif utilisé pour l'isolation du poumon a également été enregistrée.

Résultats Parmi les 40 patients inscrits à l'étude, 20 patients du groupe SET-DL et 18 du groupe BB ont été analysés. Le temps moyen (écart type) jusqu'au dégonflement complet $d u$ poumon opéré était significativement plus rapide dans le groupe $B B$ par rapport au groupe SET-DL [7,5 (3,8) min vs 36,6 $(29,1)$ min, respectivement; différence moyenne, 29,1 min; intervalle de confiance $95 \%, 1,8$ à 7,2; $P<0,001]$. Globalement, une plus importante proportion de patients $d u$ groupe $B B$ que du groupe SET-DL est parvenue à un score de 3 à cinq minutes (57\% vs $6 \%$, respectivement; $P$ $<0,004)$, dix minutes (73\% vs $14 \%$, respectivement; $P=$ $0,005)$, et $20 \mathrm{~min}(100 \%$ vs $25 \%$, respectivement; $P=$ $0,002)$ en matière de qualité du dégonflement du poumon après l'ouverture de la plèvre. La suppostion du chirurgien sur le type de dispositif était erronée dans $78 \%$ des cas dans le groupe $B B$ et $50 \%$ des patients du groupe SET-DL $(P=0,10)$.

Conclusion Le temps nécessaire jusqu'au dégonflement $d u$ poumon et la qualité du dégonflement pendant une VUP pour une CTVA étaient significativement meilleurs en utilisant un BB qu'en utilisant une SET-DL du côté gauche. Les chirurgiens n'ont pas pu déterminer de façon fiable quel dispositif était utilisé en se fondant sur le temps et la qualité du dégonflement du poumon. Cette étude a été enregistrée au ClinicalTrials.gov, numéro NCT01615263.

Video-assisted thoracoscopic surgery (VATS) is a technique increasingly used in thoracic surgery. ${ }^{1}$ A key to successful VATS surgery is maximizing intrathoracic visualization by optimizing the quality of lung isolation and deflation within the relatively closed thoracic cavity. Double-lumen endotracheal tubes (DL-ETT) have generally been considered the gold standard for lung isolation and are considered by many to offer more rapid and better quality lung collapse when compared with bronchial blockers (BB). ${ }^{2,3}$ Nevertheless, previous studies comparing lung deflation using either a DL-ETT or BB have provided conflicting results. ${ }^{4-13}$ Moreover, the majority of these studies had significant limitations. For example, some studies included open thoracotomies along with VATS; other studies used subjective and not standardized criteria to evaluate the quality of lung collapse, and few studies reported time to "complete" lung collapse. ${ }^{4,6}$ Furthermore, the efficacy of BB for lung deflation might be manufacturer/model specific as their internal BB channels, which allow for the egress of air, have different diameters. ${ }^{8,11}$

A recent systematic review and meta-analysis comparing the efficacy and adverse effects of DL-ETTs $v s$ BBs identified 22 papers on the subject, though only nine papers with relevant data were analyzed. ${ }^{14}$ The authors found no significant differences between DLETTs and BBs in the time to lung collapse or in the quality of lung deflation; however, the vast majority of these studies were in thoracotomy patients. During conventional thoracotomy, it is easy for the surgeon to compensate for a non-optimal lung deflation by using a lung retractor or direct lung manual compression. In contrast, during VATS it is more difficult for the surgeon to deal with a nonoptimal lung deflation. Thus, a thoracic surgeon could qualify lung deflation during thoracotomy as "acceptable", although the same degree of lung deflation in VATS would be considered "unacceptable". This highlights why the quality of lung deflation is of particular importance during VATS. 
In our own experience, we have found the use of BB to offer a similar or even better lung collapse than left-sided DL-ETT during VATS, particularly when a brief period of apnea is used just prior to initiating lung isolation. Despite this, the question whether BBs are similar to DL-ETTs, especially for VATS, is uncertain and has frequently been the source of considerable discussion between anesthesiologists and thoracic surgeons. Accordingly, the purpose of this study was to compare the efficacy of a BB when optimally used (i.e., with periods of apnea just prior to lung isolation and just after pleural opening) with that of a left-sided DL-ETT with respect to the time and quality of lung collapse during VATS.

\section{Methods}

This study protocol was approved (April 2012) by our local Research Ethics Board (Comité d'éthique à la recherche de l'Institut universitaire de cardiologie et de pneumologie de Québec - Université Laval). This was a prospective randomized single-blinded (i.e., only the patients and the thoracic surgeons were blinded to the group assignment) controlled study in patients requiring one-lung ventilation (OLV) for VATS. Written informed consent was obtained from consecutively scheduled adult patients undergoing OLV for elective left or right VATS. Exclusion criteria included patients with previous or anticipated difficult intubation, prior chemotherapy or thoracic radiotherapy, severe chronic obstructive pulmonary disease or asthma (forced expiratory volume in one second $<50 \%$ predicted), and pleural and/or interstitial pathology. There were some a priori post-randomization exclusions, including bronchoscopic findings precluding the use of the specific randomized devices (e.g., origin of the right upper lobe (RUL) bronchus is too close to the carina, precluding use of the $\mathrm{BB}$ ) and severe oxygen desaturation occurring at any time during the observation period (i.e., until complete lung collapse was achieved) necessitating ventilation of the non-dependent lung.

Before anesthesia induction, patients were assigned by computer-generated randomization to one of two study groups, left-sided DL-ETT (Mallinckrodt ${ }^{\mathrm{TM}}$ left endobronchial tube; Mallinckrodt Medical, Cornamaddy, Athlone, Westmeath, Ireland) or BB (Fuji Uniblocker; Fuji Systems, Tokyo, Japan) with the internal channel intentionally occluded to exclude any passive contribution to lung collapse. Just prior to anesthesia induction -and after the anesthesiologist confirmed the absence of a potentially difficult airway- research staff opened a sealed envelope indicating the device to be used. Thoracic surgeons were blinded to group assignment throughout the procedure.
Anesthesia management included application of standard monitoring ${ }^{15}$ and a standardized intravenous induction of anesthesia with propofol and sufentanil, with muscle relaxation (rocuronium) used according to local practice. Anesthesia was maintained with an inhaled anesthetic (sevoflurane or desflurane). For patients with a baseline heart rate $<100$ beats $\min ^{-1}$, intravenous glycopyrrolate $0.2 \mathrm{mg}$ was administered prior to induction to reduce the production of tracheobronchial secretions.

\section{Lung isolation methods}

After induction of anesthesia, the patient's trachea was intubated with either a single-lumen 8.0-mm internal diameter endotracheal tube (SL-ETT) for the BB group or a left-sided DL-ETT (37 Fr for females, $39 \mathrm{Fr}$ for males). All BBs were placed via the SL-ETT using a flexible bronchoscope (FOB). Bronchial blockers were positioned distally in the main bronchus with their cuff deflated. Left-sided DL-ETTs were positioned with the FOB at an appropriate depth to allow positioning the tracheal carina between the radiopaque black line of the endobronchial aspect of the DL-ETT and the upper part of the blue bronchial cuff. ${ }^{16}$ An attending anesthesiologist or a resident directly supervised by an attending anesthesiologist (who confirmed all device placements) placed the devices for both the BB group and the left-sided DL-ETT group.

Prior to OLV, mechanical ventilation operated in a volume-controlled mode with a tidal volume of 8-10 $\mathrm{mL} \cdot \mathrm{kg}^{-1}$ (ideal body weight), respiratory rate of 10 breaths $\cdot \min ^{-1}$, positive end-expiratory pressure (PEEP) of $5 \mathrm{~cm} \mathrm{H}_{2} \mathrm{O}$, and $\mathrm{F}_{\mathrm{I}} \mathrm{O}_{2}$ of 1.0. After the patients were positioned in a lateral decubitus position, the BB cuff or DL-ETT bronchial cuff was inflated under FOB guidance, and OLV was initiated using volume-controlled ventilation (tidal volume of $5-7 \mathrm{~mL} \cdot \mathrm{kg}^{-1}$ ideal body weight with a respiratory rate of $14-16$ breaths $\cdot \mathrm{min}^{-1}$, PEEP of $5 \mathrm{~cm}$ $\mathrm{H}_{2} \mathrm{O}$, and $\mathrm{F}_{\mathrm{I}} \mathrm{O}_{2}$ of 1.0). The internal channel of the $\mathrm{BB}$ was deliberately occluded. After the pleura had been open for 20 min, the $\mathrm{F}_{\mathrm{I}} \mathrm{O}_{2}$ was adjusted to maintain $\mathrm{O}_{2}$ saturation $>95 \%$.

In the left-sided DL-ETT group, lung isolation was initiated by clamping the bronchial or tracheal lumen of the Y-connector (corresponding to the lung to be isolated) and opening the corresponding lumen of the DL-ETT to allow for passive lung deflation. Just before inflating the BB balloon in the BB group, a 30-sec apnea period was instituted immediately prior to initiating OLV. A second 30 -sec apnea period, also with the BB balloon transiently deflated, was initiated at the time of the pleural incision. In the left-sided DL-ETT group, a "sham" apnea period was performed at the beginning of OLV to ensure study 
blinding of the thoracic surgeon. For the sham apnea period in the DL-ETT group, the anesthesiologist made similar gestures as in the BB group but without opening the airway or stopping the ventilation. A second "sham" apnea period was also conducted in the DL-ETT group at the time of pleural incision.

Surgeons were absent from the operating room during DL-ETT or BB placement and blinded to the airway device by means of a drape placed over the lung isolation device and the endotracheal tube. The FOB video monitor was oriented such that the surgical team could not identify the lung isolation device being used.

To assess the time of lung collapse and objectively evaluate the quality of lung deflation, we established a scoring system generally based on previously published studies. ${ }^{4-8}$ Fig. 1 outlines the standardized definition of lung collapse on a three-point visual and descriptive scale, where 1 = no lung collapse; 2 = partial lung collapse; and 3 $=$ total lung collapse. The thoracic surgeons and the three observers performing the offline video examinations of lung deflation also used this three-point scale.

The primary endpoint was the time from when the surgeon opened the pleura until complete lung collapse (i.e., score of 3 on the three-point scale) as determined from the offline analysis of video recordings taken during the procedure. For the video analysis, a DVD recorder (Sony RDRHX730, Sony Corporation, Malaysia) linked to the surgical camera (Olympus CV-180, Olympus Canada Inc., Richmond Hill, ON, Canada) was used to record the entire duration of surgery. The VOB files obtained were converted to WMV files and edited with Windows Movie Maker (Microsoft Corporation; Microsoft Canada Headquarters, Mississauga, ON, Canada). This allowed the three observers blinded to group assignment (i.e., two thoracic surgeons and one cardiothoracic anesthesia fellow) to analyze the video examination data offline (i.e., 30 -sec clips edited every five minutes from the videos recorded during VATS). The video clips reviewed were mixed from random group and time sequences and scored using the same standardized threepoint scale as previously described. Several secondary endpoints were also recorded. The offline quality of lung deflation was evaluated at standardized time points -i.e., immediately on pleural opening $(0 \mathrm{~min})$ and five, ten, and 20 min after pleural opening, using the same visual and chart scale as for the primary endpoint.

In addition to performing the offline assessments, the thoracic surgeons conducted a clinical evaluation of the time to achieve complete lung collapse and the quality of lung deflation using the same scale as for the offline evaluation. Other secondary endpoints included having the surgeon guess the type of device being used. This was done $20 \mathrm{~min}$ after pleural opening and before any exploration of the hilum. The use of any suction to assist lung collapse was also recorded.

\section{Statistical analysis}

All data were analyzed using the statistical package program SAS ${ }^{\circledR} 9.3$ (SAS Institute Inc., Cary, NC, USA).

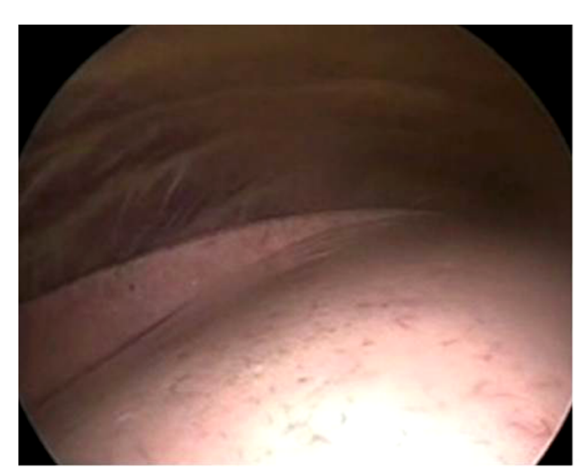

\begin{tabular}{|l|c|}
\cline { 2 - 2 } \multicolumn{1}{c|}{} & 1. No collapse \\
\hline Collapse & $+/-$ \\
\hline $\begin{array}{l}\text { Space in } \\
\text { thoracic cavity }\end{array}$ & $+/-$ \\
\hline Atelectasis & - \\
\hline Purple color & - \\
\hline Satisfactory & - \\
\hline
\end{tabular}

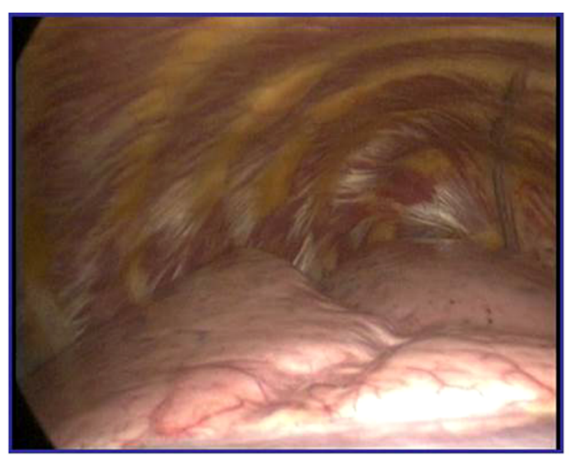

\begin{tabular}{|c|}
\hline 2. Partial collapse \\
\hline+ \\
\hline+ \\
\hline+ \\
\hline$+/-$ \\
\hline+ \\
\hline
\end{tabular}

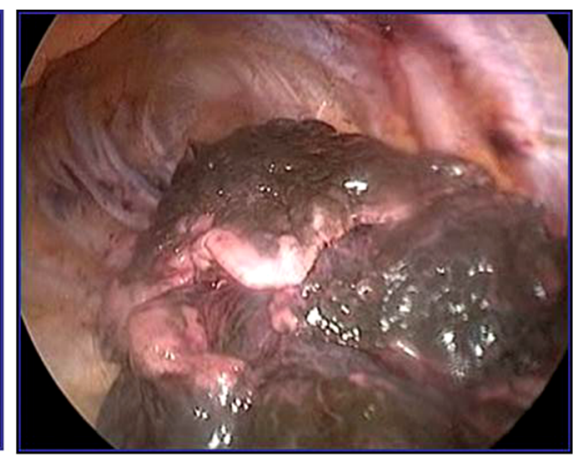

\begin{tabular}{|c|}
\hline 3. Complete collapse \\
\hline++ \\
\hline++ \\
\hline++ \\
\hline++ \\
\hline++ \\
\hline
\end{tabular}

Fig. 1 Lung collapse scoring system incorporating both visual and descriptive features. A score of $1=$ no collapse; a score of $2=$ partial collapse; a score of $3=$ complete lung collapse. Although scores of 2 and 3 were considered to indicate satisfactory surgical conditions, the primary study endpoint targeted a score of 3 
Our sample size estimate was based on the time to complete lung collapse evaluated by video examination (i.e., our primary endpoint). We used data from Campos et $a{ }^{6}{ }^{6}$ where they reported a mean (standard deviation [SD]) collapse time of 18 (7.2) min after initiation of OLV in the DL-ETT group. Assuming a $40 \%$ difference between groups with an alpha of 0.05 and a power of 0.80 , we estimated that we would require a sample size of 18 patients per group. We randomized 40 patients $(20$ subjects per group) to account for potential post-randomization exclusions.

Clinical observation data were log-transformed prior to undergoing analysis of variance (ANOVA). Statistical results from these parameters were expressed with transformed values. Tukey's multiple comparison technique was applied post hoc to the ANOVA to compare pairs of group means. The univariate normality assumption was verified using the graphical representations and the Shapiro-Wilk test. The Brown-Forsythe variation of Levene's test statistic was used to verify the homogeneity of variances. The data regarding time to lung collapse were analyzed using a mixed model with heterogeneous variances for the two techniques. Quality of lung collapse was analyzed with Fisher's exact test. All reported $P$ values are two sided. As the secondary outcome of quality of lung collapse was evaluated at four different times $(0,5,10$, and $20 \mathrm{~min}$ after lung isolation), a Bonferroni correction was applied and $P<0.0125$ was considered significant.

Video examination data were also secondarily analyzed using a model based on the probability of observing a given lung deflation score at a given time. From the model, the parameter $\mathrm{T}_{50,3}$ (time associated with $50 \%$ probability of observing a complete lung collapse score of 3) was estimated using the solver function in Microsoft Excel. The Appendix includes a description and analysis of the model. The magnitude of interobserver agreement regarding the video examination data was determined using a weighted Kappa statistic where 0-0.20 would denote slight agreement; 0.21-0.40, fair agreement; 0.410.60, moderate agreement; 0.61-0.80, substantial agreement, and $>0.81$ almost perfect agreement. ${ }^{17}$

\section{Results}

Eighty-eight patients undergoing elective lung resection by VATS were screened during a five-month period. Fortyeight patients met exclusion criteria and 40 patients were subsequently randomized, 20 in each group (Fig. 2). Two patients were excluded after randomization, both within the BB group. The first patient was excluded due to an anatomic variation of the RUL bronchus precluding use of a BB. The second patient was excluded after experiencing a severe episode of arterial oxygen desaturation that happened shortly after initiating OLV. This episode necessitated ventilation of the non-dependent lung. Both groups were similar in terms of their demographic variables (Table 1), and there was no difference between groups regarding left- or right-sided surgery.

The remaining results are presented in two parts, the first part is the video examination data (i.e., primary outcome) obtained from the offline review of the video clips edited from the video recorded during the VATS procedures. Due to technical problems, recordings from eight patients (four in each group) are not available. The level of agreement between the three observers of video clip examinations showed substantial interobserver agreement (kappa $=0.68$ ). The second part is the clinical observation data obtained during surgery (Fig. 2).

Results for the primary endpoint of this study are summarized in Table 2 . The video review time intervals from pleural opening until complete lung collapse showed a significantly faster mean (SD) time to complete collapse of the operative lung using the BB compared with using the DL-ETT [7.5 (3.8) min vs 36.6 (29.1) min, respectively; mean difference, $29.1 \mathrm{~min} ; 95 \%$ confidence interval $(\mathrm{CI})$, 1.8 to $7.2 ; P<0.001]$.

In the video examination data (Table 3), a higher proportion of patients in the BB group achieved a quality of lung collapse score of 3 after pleural opening when compared with the DL-ETT group at five minutes $(57 \% \mathrm{vs}$ $6 \%$, respectively; $P=0.004)$, ten minutes $(73 \%$ vs $14 \%$, respectively; $P=0.005)$, and $20 \mathrm{~min}(100 \%$ vs $25 \%$, respectively; $P<0.001)$.

In the clinical observation data, the mean (SD) time from pleural opening until complete lung collapse was faster using the BB than using the DL-ETT [10.3 (10.6) min vs 22.9 (21.4) min, respectively; mean difference, 12.5 min; $95 \% \mathrm{CI}, 1.1$ to $3.8 ; P=0.05]$. We observed better quality lung deflation (Table 4 ) in favour of the BB group following pleural opening at five, ten, and $20 \mathrm{~min}$. At 20 min, the thoracic surgeons verified total lung collapse in $78 \%$ of the BB group vs $45 \%$ of the DL-ETT group $(P=$ $0.05)$. The mean (SD) interval from beginning OLV until pleural opening was not different between the DL-ETT and BB groups [18.0 (6.8) min vs 22.3 (6.2) min, respectively; $P=0.15)$.

The surgeons' guesses regarding the type of lung isolation device were correct in only four of $18(22 \%)$ patients in the BB group and ten of $20(50 \%)$ patients in the left-sided DL-ETT group (effect size difference, 28\%; 95\% CI, -8 to $54 ; P=0.10)$. Combining all groups, the surgeons' guesses were correct in only 14 of $38(37 \%)$ cases. Rescue suction was used only once in the BB group and not used at all in the left-sided DL-ETT group $(P=0.47)$. There was 


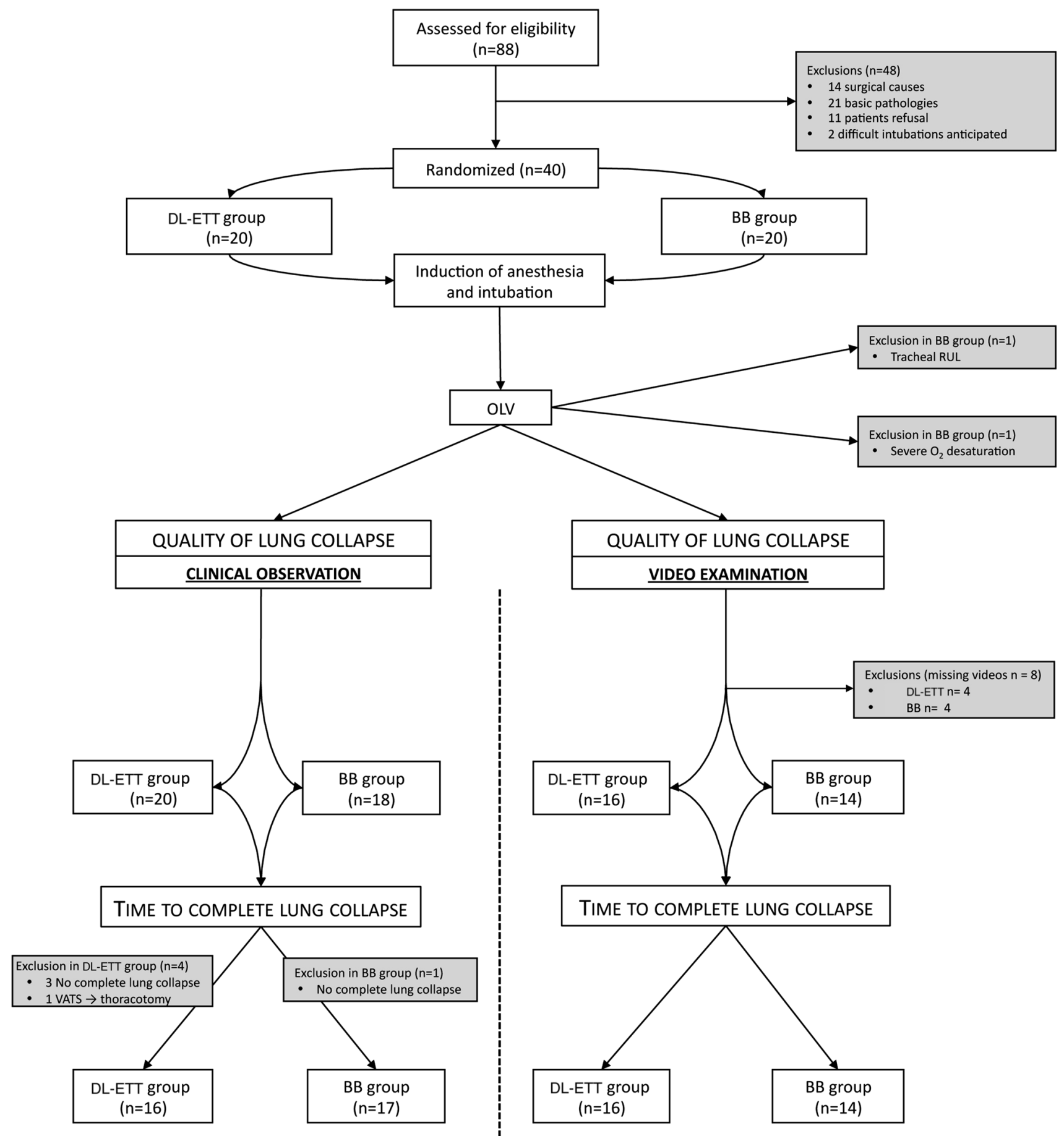

Fig. 2 CONSORT diagram

no conversion in thoracotomy secondary to poor exposure due to inadequate lung collapse.

\section{Discussion}

Our results show that, in patients having elective VATS, the time interval from pleural opening until objective assessment of complete lung collapse is significantly faster with a BB than with a left-sided DL-ETT. In addition, when scoring the quality of lung deflation -in both the real-time and offline assessments- at five, ten, and $20 \mathrm{~min}$ from pleural opening, the BB showed a significantly better lung deflation than the leftsided DL-ETT. Furthermore, when asked which method was being used for lung isolation, the surgeons were correct only $37 \%$ of the time (with no differences between groups), 
suggesting that the two devices could be used interchangeably without the surgeon noticing any differences.

Our study population is somewhat different from prior studies of OLV techniques as it included only patients having VATS. This study population represents over $95 \%$ of our hospital's elective intrathoracic procedures, and this appears to be a growing trend in many thoracic surgical centres. ${ }^{18}$ Contrary to most other published studies, we chose to select a homogenous population, and therefore, we excluded patients with pleural pathology, severe parenchymal disease, and previous thoracic surgery or thoracic radiotherapy as these conditions could interfere with lung collapse and introduce bias.

In addition to real-time clinical assessments of the quality of lung collapse, another strength of our study was our means for acquiring optimally objective data -i.e., the quality of lung collapse was assessed using both offline video review and clinical observation. Our definition of lung collapse was very conservative in that it meant complete collapse of all lung areas and was graded using a standardized visual scale (Fig. 1). Also, as there was substantial agreement between the three observers of video clips (kappa $=0.68$ ), we consider the video evaluation as being more valuable than the surgeon's direct clinical observation, which may be influenced by different factors during the surgery.

Table 1 Demographic and surgical characteristics

\begin{tabular}{lll}
\hline DATA & $\begin{array}{l}\text { DL-ETT } \\
(n=20)\end{array}$ & BB $(n=18)$ \\
\hline Age $(\mathrm{yr})$ & $63(11)$ & $62(8)$ \\
Male, $n(\%)$ & $9(45)$ & $8(44)$ \\
Ideal Weight $(\mathrm{kg})$ & $69.6(6.4)$ & $68.2(9.9)$ \\
BMI $\left(\mathrm{kg} \cdot \mathrm{m}^{-2}\right)$ & $27.9(6.1)$ & $28.3(5.1)$ \\
FEV1/FVC $(\%)$ & $71.4(6.7)$ & $71.9(7.5)$ \\
FEV1 $(\%)$ & $87.1(19.2)$ & $90.6(6.8)$ \\
FVC $(\%)$ & $96.5(17.4)$ & $98.6(16.7)$ \\
Right-sided isolation, $n(\%)$ & $10(47.6)$ & $11(52.4)$ \\
Left-sided isolation, $n(\%)$ & $10(58.8)$ & $7(41.2)$ \\
\hline
\end{tabular}

Values are expressed as mean (standard deviation) unless otherwise indicated. $\mathrm{BB}=$ bronchial blockers; $\mathrm{BMI}=$ body mass index; $\mathrm{DL}-\mathrm{ETT}=$ double-lumen endotracheal tubes; FEV1 = forced expiratory volume in one second; FVC = forced vital capacity
One novel aspect of our study was using two periods of apnea when using the $\mathrm{BB}$ for lung isolation; this represents a recent refinement in the $\mathrm{BB}$ technique. Indeed, prior publications have reported one period of apnea -i.e., prior to initiating OLV, and few have described the use of any apnea period prior to initiating OLV. ${ }^{8-10}$ They showed similar or inferior results compared with using the DLETT. The results we obtained by adding a second apnea period at the time of pleural opening showed a decrease in time to obtain complete lung collapse and an important increase in the quality of lung deflation. In our view, the addition of a second period of apnea synchronized with the surgical pleural opening is imperative to obtain optimal lung collapse with the BB during VATS.

Lung collapse following lung isolation occurs in two phases. The first phase of lung collapse occurs rather promptly (i.e., within the first few minutes) due to the inherent elastic recoil of the lung as soon as ambient air freely enters the thoracic cavity at the pleural opening. This rapid but partial collapse ceases presumably due to closure of small airways. In the second phase, lung collapse is dependent on continuous gaseous diffusion and secondary absorption atelectasis. ${ }^{18}$ Therefore, there are two possible explanations for the shorter time to obtain total lung collapse and better lung deflation observed with the BB.

First, the longer time period for lung deflation with a left-sided DL-ETT involves air movement from the mediastinal shifts during OLV with the non-dependent lung side open to room air. It is conceivable that, compared with the closed $\mathrm{BB}$, significant quantities of $\mathrm{O}_{2}$ in the lung are replaced due to passive inflow of ambient air into the non-dependent lung, which therefore impedes the second phase of lung deflation with the left-sided DL-ETT.

Another reason that could occur concurrently is the occasional anatomical obstruction that can happen at the distal portion of the bronchial lumen when the left-sided DL-ETT is used for left side lung isolation or at the distal extremity of the tracheal lumen when the left-sided DL-ETT is used for right side lung isolation. We regularly observe this anatomical obstruction during FOB when placing a leftsided DL-ETT once the patient is in the lateral position. Lateral positioning, as it relates to lung deflation, may

Table 2 Lung collapse data - time intervals from pleural opening until complete lung collapse

\begin{tabular}{|c|c|c|c|c|c|}
\hline & DL-ETT & $\mathrm{BB}$ & mean difference & $95 \% \mathrm{CI}$ & $P$ \\
\hline \multirow[t]{2}{*}{ Video Review } & $n=11$ & $n=14$ & & $3.6(1.8$ to 7.2$)$ & $<0.001$ \\
\hline & $36.6(29.1) \mathrm{min}$ & $7.5(3.8) \mathrm{min}$ & $29.1 \mathrm{~min}$ & & \\
\hline \multirow[t]{2}{*}{ Clinical Evaluation } & $n=16$ & $n=17$ & & $2.0(1.1$ to 3.8$)$ & 0.047 \\
\hline & $22.9(21.4) \min$ & $10.3(10.6) \mathrm{min}$ & $12.6 \mathrm{~min}$ & & \\
\hline
\end{tabular}

Values are expressed as mean (standard deviation). BB = bronchial blockers; CI = confidence interval; DL-ETT = double-lumen endotracheal tubes 
Table 3 Quality of lung deflation obtained by video examinations

\begin{tabular}{|c|c|c|c|c|c|c|c|c|c|}
\hline \multirow{2}{*}{$\begin{array}{l}\text { Video examinations } \\
\text { DEFINITIONS }\end{array}$} & \multirow{2}{*}{$\begin{array}{l}\text { TIME (min) } \\
\text { SCORE }\end{array}$} & \multicolumn{2}{|l|}{0} & \multicolumn{2}{|l|}{5} & \multicolumn{2}{|l|}{10} & \multicolumn{2}{|l|}{20} \\
\hline & & $\begin{array}{l}\mathrm{BB} \\
n(\%)\end{array}$ & $\begin{array}{l}\text { DL-ETT } \\
n(\%)\end{array}$ & $\begin{array}{l}\mathrm{BB} \\
n(\%)\end{array}$ & $\begin{array}{l}\text { DL-ETT } \\
n(\%)\end{array}$ & $\begin{array}{l}\mathrm{BB} \\
n(\%)\end{array}$ & $\begin{array}{l}\text { DL-ETT } \\
n(\%)\end{array}$ & $\begin{array}{l}\mathrm{BB} \\
n(\%)\end{array}$ & $\begin{array}{l}\text { DL-ETT } \\
n(\%)\end{array}$ \\
\hline Total $(n)$ & & 14 & 16 & 14 & 16 & 11 & 14 & 14 & 16 \\
\hline No collapse & 1 & $3(21)$ & $10(63)$ & $0(0)$ & $3(19)$ & $0(0)$ & $0(0)$ & $0(0)$ & $0(0)$ \\
\hline Partial collapse & 2 & $10(71)$ & $6(38)$ & $6(43)$ & $12(75)$ & $3(27)$ & $12(86)$ & $0(0)$ & $10(63)$ \\
\hline Total collapse & 3 & $1(7)$ & $0(0)$ & $8(57)$ & $1(6)$ & $8(73)$ & $2(14)$ & $14(100)$ & $4(25)$ \\
\hline$P^{*}$ value & & 0.04 & & 0.004 & & 0.005 & & $<0.001$ & \\
\hline
\end{tabular}

* Statistical significance threshold set at $P<0.0125$ (Boneferroni correction). BB = bronchial blockers; DL-ETT $=$ double-lumen endotracheal tubes

Table 4 Quality of lung deflation obtained by clinical observations

\begin{tabular}{|c|c|c|c|c|c|c|c|c|c|}
\hline \multirow{2}{*}{$\begin{array}{l}\text { Clinical observations } \\
\text { DEFINITIONS }\end{array}$} & \multirow{2}{*}{$\begin{array}{l}\text { TIME (min) } \\
\text { SCORE }\end{array}$} & \multicolumn{2}{|l|}{0} & \multicolumn{2}{|l|}{5} & \multicolumn{2}{|l|}{10} & \multicolumn{2}{|l|}{20} \\
\hline & & $\begin{array}{l}\mathrm{BB} \\
n(\%)\end{array}$ & $\begin{array}{l}\text { DL-ETT } \\
n(\%)\end{array}$ & $\begin{array}{l}\mathrm{BB} \\
n(\%)\end{array}$ & $\begin{array}{l}\text { DL-ETT } \\
n(\%)\end{array}$ & $\begin{array}{l}\mathrm{BB} \\
n(\%)\end{array}$ & $\begin{array}{l}\text { DL-ETT } \\
n(\%)\end{array}$ & $\begin{array}{l}\mathrm{BB} \\
n(\%)\end{array}$ & $\begin{array}{l}\text { DL-ETT } \\
n(\%)\end{array}$ \\
\hline Total $(n)$ & & 18 & 20 & 18 & 20 & 18 & 20 & 18 & 20 \\
\hline No collapse & 1 & $1(6)$ & $2(10)$ & $0(0)$ & $1(5)$ & $0(0)$ & $0(0)$ & $0(0)$ & $0(0)$ \\
\hline Partial collapse & 2 & $13(72)$ & $15(75)$ & $8(44)$ & $15(75)$ & $6(33)$ & $14(70)$ & $4(22)$ & $11(55)$ \\
\hline Total collapse & 3 & $4(22)$ & $3(15)$ & $10(56)$ & $4(20)$ & $12(67)$ & $6(30)$ & $14(78)$ & $9(45)$ \\
\hline$P^{*}$ value & & 0.87 & & 0.04 & & 0.05 & & 0.05 & \\
\hline
\end{tabular}

* Statistical significance threshold set at $P<0.0125$ (Boneferroni correction). BB = bronchial blockers; DL-ETT = double-lumen endotracheal tubes

induce a downward gravity-dependent movement of the hilum and produce variable obstruction of the distal endobronchial lumen or the tracheal lumen near the carina. With a $\mathrm{BB}$, there is probably less chance of an anatomical obstruction of the distal endobronchial lumen of the SLETT. This is due to better support offered by the trachea and less influence from gravity compared with the bronchus. These speculative explanations need further clinical study for a better understanding of their significance.

Rescue suction was allowed only when the visual deflation score was at level 1 (i.e., poor deflation) and used only once in the BB group. Campos et al. used suction in more than $50 \%$ of lung isolation cases when using the BB and frequently when using the left-sided DL-ETT. ${ }^{4-6}$ Suction was frequently used in more than $50 \%$ of the published studies, only two studies did not use it in their protocol. ${ }^{8,10}$ Deliberately occluding the internal channel of the BB (small diameter, $2 \mathrm{~mm}$; effective length, $67 \mathrm{~cm}$ ), allows extrapolation of the results to every commercially available BB and confirms our impression that this channel does not participate passively in lung deflation. ${ }^{6,8,11}$

There were some limitations to this study. We did not obtain data for the video examination from eight patients (four patients in each group) due to technical problems. Even with these missing data, the results of the video examination data are in accordance with the clinical observations in favour of the BB. Another limitation is that our population was restricted to patients presenting good lung recoil, as patients with potentially altered lung recoil were excluded from the study. Nevertheless, patients with pulmonary pathologies associated with bad recoil correspond to a population in which the BB could be used, but rarely with optimal result.

\section{Conclusion}

This study shows that use of a BB (with two apnea periods) results in a faster time to obtain lung collapse and a superior quality of lung deflation when compared with use of a leftsided DL-ETT during elective VATS. Furthermore, in most patients, thoracic surgeons could not identify the type of device used for lung isolation. These results are relevant to clinical practice as this BB protocol is easily applicable in patients undergoing lung resection by VATS on both lungs. Furthermore, as the internal channel of the BB was occluded throughout the study, the results can be extrapolated to a wide variety of BBs. 


\section{Funding None.}

Conflicts of interest None declared.

Author contributions Jean S. Bussières, Jérôme Lemieux, José Luis Carrasco del Castillo, and Massimo Conti made substantial contributions to the conception and design of the study. Jean S. Bussières, Jérôme Lemieux, Jacques Somma, and Paula Ugalde made substantial contributions to the analysis and interpretation of data. Jean S. Bussières, Jérôme Lemieux, José Luis Carrasco del Castillo, Jacques Somma, Paula Ugalde, and Massimo Conti made substantial contributions to drafting the article and revising the article critically for important intellectual content. José Luis Carrasco del Castillo made substantial contributions to the acquisition of data. Nathalie Gagné was involved in the acquisition of data and drafting the article. Nathalie Gagné and Yves Lacasse were involved in revising the manuscript critically for important intellectual content.

Editorial responsibility This submission was handled by Dr. Hilary P. Grocott, Editor-in-Chief, Canadian Journal of Anesthesia.

\section{Appendix}

The model, which has been described in a previous publication, ${ }^{19}$ is based on the probability of observing a given lung deflation score at a given time according to the following relationship:

$P($ score $\geq d S)=\frac{\operatorname{Time}^{N}}{\operatorname{Time}^{N}+\operatorname{Time}_{50, d S}^{N}}$.

where Time is the elapsed time since the initiation of OLV; $N$ is the Hill coefficient related to the steepness of the relationship; $d S$ is the deflation score; and Time ${ }_{50, d S}$ is the time when there is a $50 \%$ chance of observing a deflation score of $d S$ or greater.

A specific case of equations 1 is equation 2 .

$P($ score $\geq 1)=1$

Equation 2 is obvious since the probability of observing a score of 1 or greater is $100 \%$.

Equation 1 predicts the probability of observing a score greater or equal to a given score rather than observing a given score. The probability of observing a score equal to 1,2 , or 3 is derived from the following equation.

$P($ score $=d S)=($ score $\geq d S)-P($ score $\geq d S+1)$

where $d S$ is equal to 1,2 , or 3 .

From equations 2 and 3:

$P($ score $=1)=1-P($ score $\geq 2)$

$P($ score $=2)=P($ score $\geq 2)-P($ score $\geq 3)$

$P($ score $=3)=P($ score $\geq 3)$
Equation 6 is self-evident since there is no score possible above 3 .

The likelihood (LL) of the model is the product of the probability of each observed deflation score. Parameters Time $_{50, d S}$ and $\mathrm{N}$ where estimated by using the solver function of Microsoft Excel to minimize the objective function -2LL.

\section{References}

1. Klapper J, D'Amico TA. VATS versus open surgery for lung cancer resection: moving toward a minimally invasive approach. J Natl Compr Can Netw 2015; 13: 162-4.

2. Neustein SM. Pro: bronchial blockers should be used routinely for providing one-lung ventilation. J Cardiothorac Vasc Anesth 2015; 29: 234-6.

3. Brodsky JB. Con: a bronchial blocker is not a substitute for a double-lumen endobronchial tube. J Cardiothorac Vasc Anesth 2015; 29: 237-9.

4. Campos JH, Reasoner DK, Moyers JR. Comparison of a modified double-lumen endotracheal tube with a single-lumen tube with enclosed bronchial blocker. Anesth Analg 1996; 83: 1268-72.

5. Campos JH, Hallam EA, Ueda K. Lung isolation in the morbidly obese patient: a comparison of a left-sided double-lumen tracheal tube with the Arndt(R) wire-guided blocker. Br J Anaesth 2012; 109: 630-5.

6. Campos JH, Kernstine KH. A comparison of a left-sided Broncho-Cath with the torque control blocker univent and the wire-guided blocker. Anesth Analg 2003; 96: 283-9.

7. Bauer C, Winter C, Hentz JG, Ducrocq X, Steib A, Dupeyron JP. Bronchial blocker compared to double-lumen tube for one-lung ventilation during thoracoscopy. Acta Anaesthesiol Scand 2001; 45: 250-4.

8. Dumans-Nizard V, Liu N, Laloe PA, Fischler M. A comparison of the deflecting-tip bronchial blocker with a wire-guided blocker or left-sided double-lumen tube. J Cardiothorac Vasc Anesth 2009; 23: 501-5.

9. Yoo JY, Kim DH, Choi H, Kim K, Chae YJ, Park SY. Disconnection technique with a bronchial blocker for improving lung deflation: a comparison with a double-lumen tube and bronchial blocker without disconnection. J Cardiothorac Vasc Anesth 2014; 28: 904-7.

10. Mourisse J, Liesveld J, Verhagen A, et al. Efficiency, efficacy, and safety of EZ-blocker compared with left-sided double-lumen tube for one-lung ventilation. Anesthesiology 2013; 118: 550-61.

11. Narayanaswamy $M, M c R a e K$, Slinger $P$, et al. Choosing a lung isolation device for thoracic surgery: a randomized trial of three bronchial blockers versus double-lumen tubes. Anesth Analg 2009; 108: 1097-101.

12. Ruetzler K, Grubhofer $G$, Schmid W, et al. Randomized clinical trial comparing double-lumen tube and EZ-blocker for singlelung ventilation. Br J Anaesth 2011; 106: 896-902.

13. Grocott HP, Darrow TR, Whiteheart DL, Glower DD, Smith MS Lung isolation during port-access cardiac surgery: double-lumen endotracheal tube versus single-lumen endotracheal tube with a bronchial blocker. J Cardiothorac Vasc Anesth 2003; 17: 725-7.

14. Clayton-Smith A, Bennett K, Alston RP, et al. A comparison of the efficacy and adverse effects of double-lumen endobronchial tubes and bronchial blockers in thoracic surgery: a systematic review and meta-analysis of randomized controlled trials. J Cardiothorac Vasc Anesth 2015; 29: 955-66. 
15. Merchant $R$, Chartrand D, Dain $S$, et al. Guidelines to the Practice of Anesthesia Revised Edition 2012. Can J Anesth 2012; 59: 63-102.

16. Fortier $G$, Cote D, Bergeron C, Bussieres JS. New landmarks improve the positioning of the left Broncho-Cath double-lumen tube-comparison with the classic technique. Can J Anesth 2001; 48: 790-4.

17. Kramer MS, Feinstein AR. Clinical biostatistics. LIV. The biostatistics of concordance. Clin Pharmacol Ther 1981; 29: 111-23.
18. Shah RD, D'Amico TA. Modern impact of video assisted thoracic surgery. J Thorac Dis 2014; 6(Suppl 6): S631-6.

19. Somma J, Donner A, Zomorodi K, et al. Population pharmacodynamics of midazolam administered by target controlled infusion in SICU patients after CABG surgery. Anesthesiology 1998; 89: 1430-43. 